\title{
Variación de la línea de costa en la aldea de Cedeño, y cartografía de amenaza ante marejadas y ascenso del nivel del mar
}

\author{
Juan Angel del Cid Gómez ${ }^{1}$ \\ José David Cáceres ${ }^{2}$
}

\section{RESUMEN}

La aldea de Cedeño es altamente vulnerable al embate de los fenómenos hidro meteorológicos que periódicamente ocurren en sus playas (Marejadas), a esto se le debe sumar los efectos que producirá el cambio climático. Todo lo anterior ocasionara daños irreversibles como retroceso de la línea de costa, inundaciones debido al aumento del océano, perdida de humedales, intrusión de agua salina, y desplazamiento de personas. Los impactos negativos en el sistema territorial y por ende en la calidad de vida de sus pobladores serán grandes. El objetivo general, consistió en elaborar una línea base sobre los patrones de variabilidad de la costa de la Aldea de Cedeño (tasas de erosión/acreción), además de la cartografía de amenazas ante fenómenos naturales (Mapas de inundación marejadas/ inundación ante el ascenso del mar), que sirva de apoyo para proponer políticas de planificación y gestión del territorio adecuadas.

La metodología empleada se basó en análisis geoespacial, usando herramientas de sistemas de información geográfica, teledetección, participación ciudadana y herramientas estadísticas. Los resultados evidenciaron un comportamiento erosivo en las playas de la aldea de Cedeño, así como también una gran área vulnerable a inundación ante las marejadas y escenarios de ascenso del nivel del mar.

Palabras clave: Erosión, acreción, transectos, inundación, línea de costa

\footnotetext{
${ }^{1}$ Beneficiario de una beca de estudiante de posgrado, DICYP-UNAH. Estudiante de la Maestría en Ordenamiento y Gestión del Territorio, Facultad de Ciencias Espaciales, UNAH: juandelcid_08@yahoo.es

${ }^{2}$ Asesor, Profesor del Departamento de Ciencia y Tecnologías de la Información Geográfica, Facultad de Ciencias espaciales, UNAH: josedavid.caceres@gmail.com
} 


\section{ABSTRACT}

The village of Cedeño is highly vulnerable to the onslaught of hydrometeorological phenomena that periodically occur on its beaches (Swells), to which must be added the effects produced by climate change. All of the above will cause irreversible damage such as retreat of the coastline, flooding due to the increase of the ocean, loss of wetlands, intrusion of saline water, and displacement of people. The negative impacts on the territorial system and therefore on the quality of life of its inhabitants will be great. The general objective was to develop a baseline on the variability patterns of the Cedeño Aldea coast (erosion / accretion rates), as well as the cartography of threats to natural phenomena (flood tidal maps / inundation floods) of the sea), which serves as a support to propose appropriate planning and land management policies.

The methodology used was based on geospatial analysis, using tools of geographic information systems, remote sensing, citizen participation and statistical tools. The results showed an erosive behavior on the beaches of the village of Cedeño, as well as a large area vulnerable to flooding before the swells and scenarios of sea level rise.

Keywords: Erosion, accretion, transects, flood, shoreline 


\section{OBJETIVOS}

Generar una línea base sobre los patrones de movimiento de la línea de costa, que sirvan de apoyo para establecer políticas adecuadas de ordenamiento y gestión territorial en ambientes marino costeros.

\section{INTRODUCCIÓN}

La aldea de Cedeño es un territorio turístico de fácil acceso popular, sin embargo es altamente vulnerable a amenazas hidrometeorológicas, ascenso del nivel del mar, marejadas, y temporales. Uno de los problemas actuales son las marejadas que periódicamente inundan gran parte de su territorio. Las marejadas más recientes se dieron en los años, 2014, y 2015y 2016, ocasionado cuantiosas pérdidas monetarias por destrucción de infraestructura, erosión costera, y cientos de damnificados.

Según el Grupo intergubernamental de expertos sobre cambio climático (IPCC, 2013), el calentamiento global, podría tener efectos dramáticos en el presente siglo en Centroamérica, considera "altamente probable" el aumento de la erosión costera, mientras que las predicciones más pesimistas tienen un escenario de elevación del mar de 0.22-0.38 cm para el periodo 2046-2065, y de 45 a $82 \mathrm{~cm}$ para el periodo entre 2081-2100. Existe un vacío de información sobre la variación de línea de costa que sirvan de apoyo a implementar políticas de planificación y gestión del territorio. Los métodos usados para el monitoreo de la variación de la línea costera y planteamiento de escenarios de inundación por ascenso del nivel del mar en la aldea de Cedeño, son métodos de análisis geoespacial, y metodologías usadas en estudios similares, por Fletcher, y otros (2012).

La temporalidad para observar la acreción/erosión de la playa fue de 33 años entre 1982 y 2015. Se usaron imágenes satelitales cuyo pre proceso fue en Google Earth Engine, en tanto que el post proceso y cartografía se realizó en Arcgis 10.3, en tanto las estadísticas de los datos resultantes se elaboraran en Excell con técnicas de regresión lineal. Finalmente la cartografía de inundación a marejadas se construyó con información ofrecida por la experiencia de los pobladores, por otra parte el mapa de inundación debido a aumento del nivel del mar, tomara el modelo elevación digital, las proyecciones de ascenso del mar del IPCC (2013), más la marea meteorológica y mareas astronómicas. 


\section{ZONA DE ESTUDIO}

Comprende las playas de Los Delgaditos, Cedeño Centro, playa El Edén, y Punta Condega (Ver Figura 1), todas estas pertenecen a la Aldea de Cedeño, localizada en el Municipio de Marcovia, Departamento de Choluteca, Honduras, a 167 km de la ciudad capital Tegucigalpa, dichas zonas se ubican entre las coordenadas con proyección UTM 451646 E , 1459572 N y 453442E, 1454069N. Las playas de la aldea de Cedeño fueron divididas en 3 sectores, Los Delgaditos, Cedeño centro y Playa El Edén.

\section{Figura 1. Ubicación espacial de la investigación}

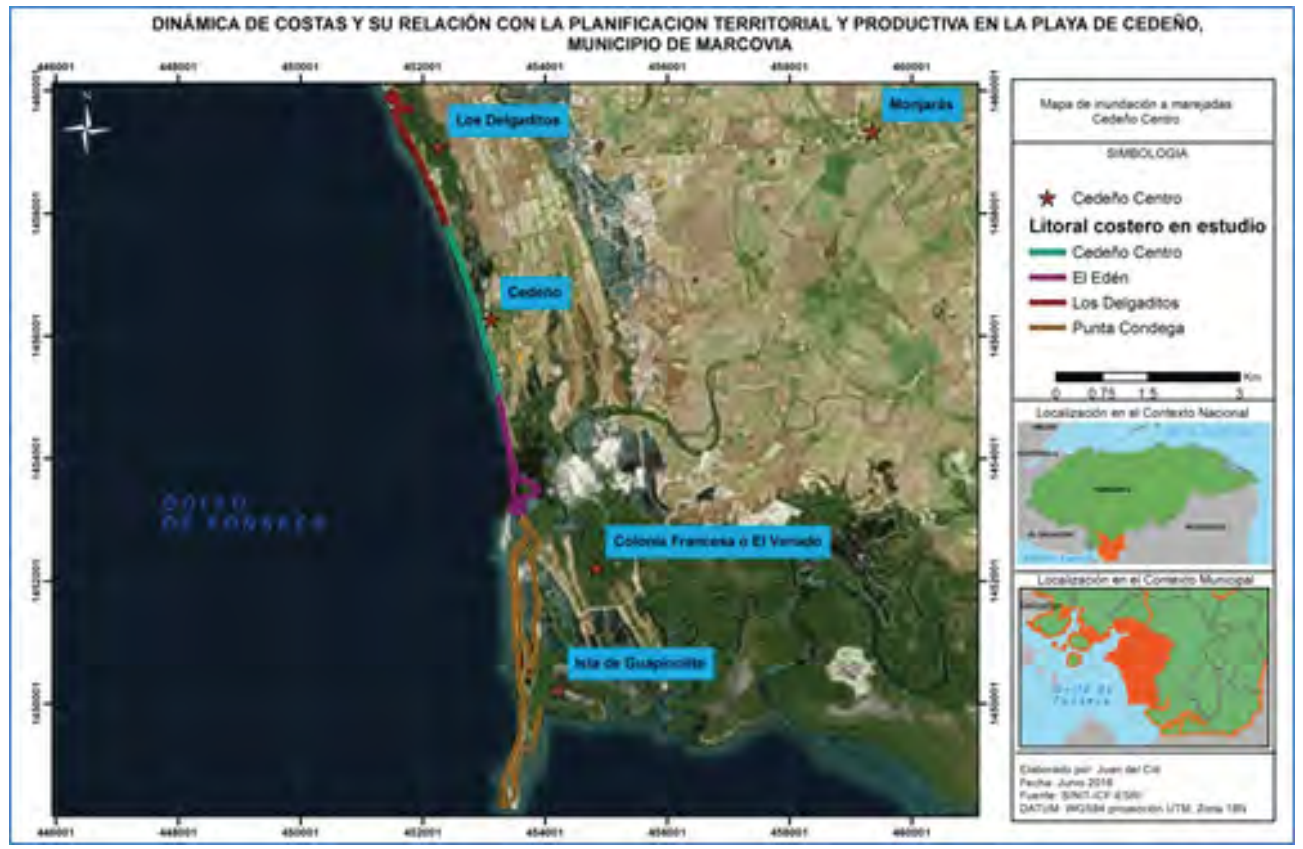

Fuente: Elaboración Propia

\section{MÉTODOS Y HERRAMIENTAS}

Autores como Fletcher, y otros (2012); Ojeda Zújar, y otros, (2013); Castillo Charris \& Gamarra Mendoza, (2014); Ministerio de Medio Mabiente y Recursos Naturales de El Salvador, (2012), han propuesto métodos y técnicas para determinar las variaciones que se producen en la costa, productos de múltiples factores, además de criterios 
técnicos para generar mapas de inundación tomando en cuenta principalmente escenarios de ascenso del nivel del mar.

\section{Imágenes históricas}

El análisis de la variación de la línea de costa tiene una temporalidad de 33 años de 1982 a 2015, usando 2 fotos áreas y 22 imágenes Satelitales Landsat 7 y 8, comparando un total de 2 imágenes por año, una en la temporada de verano (enero - mayo), otra al final del invierno (septiembre - diciembre), en la tabla 1 se muestra la descripción de las imágenes usadas.

Tabla 1. Descripción de las imágenes históricas usadas en el estudio

\begin{tabular}{|c|c|c|c|c|c|c|}
\hline Tipo de Muestra & $\begin{array}{c}\text { Fuente } \\
\text { Fotografia Aérea }\end{array}$ & $\begin{array}{c}\text { Instituto de la } \\
\text { Propiedad }\end{array}$ & $\begin{array}{c}\text { Tamaño } \\
\text { de pixel }\end{array}$ & Fecha & Cantidad & Tipo de Datos \\
\hline $\begin{array}{c}\text { Imagen satelital } \\
\text { Landsat7,ETM+ }\end{array}$ & USGS & Variable & $15 \mathrm{mts}$ & $2005-2012$ & 16 & Raster \\
\hline $\begin{array}{c}\text { Imagen satelital } \\
\text { Landsat8, OU }\end{array}$ & USGS & Variable & $15 \mathrm{mts}$ & $2013-2015$ & 6 & Raster \\
\hline
\end{tabular}

Fuente: Elaboración Propia

\section{Pre proceso de las imágenes}

Hantson, y otros, (2011), coincide con otros autores en que las correcciones geometricas, y correcciones radiometricas, son importantes para su posterior uso en el análisis multitemporal de los recursos naturales y ambiente y la consecuente obtención de productos de calidad.

Debido a que casi el 70\% de las imágenes usadas son del sensor Landsat 7, la primera corrección a estas fue rellenar los vacíos debido al bandeado de sus imágenes 0 comúnmente llamado efecto gaps (Ver Figura 2, izquierda), como segundo paso se realizó la corrección a tope de atmosfera. En todo el proceso anterior se usó una herramienta que recientemente salió al uso público, como es Google Earth Engine, el cual es una plataforma que usa lenguaje de programación JavaScript (ver Figura 2, derecha). 
Figura 2. Imagen Landsat 7 con error de bandeado (izquierda) y editor de códigos en Google Earth Engine (derecha)*
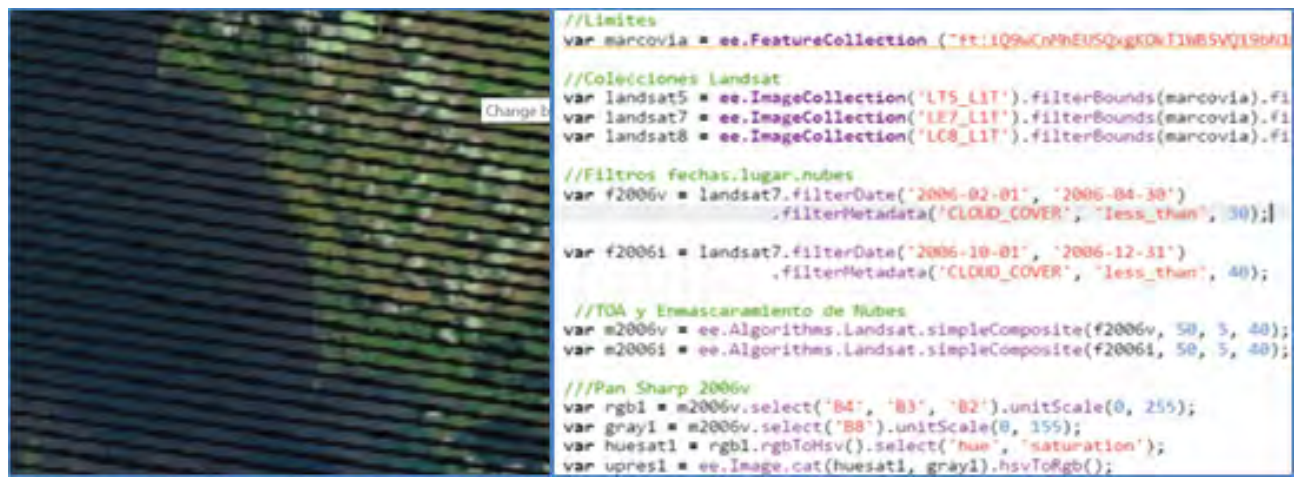

Fuente; USGS, Google Earth Engine

Posteriormente se realizó la Georreferenciación de las imágenes, el sistema de proyección usado fue Universal Transversal de Mercator (UTM) en el Datum, World Geodetic System 84 (WGS 83), zona 16 Norte. Las imágenes fueron corregidas geométricamente en el software Arcgis 10.3. En cada imagen se colocó un total de 50 puntos de control (PC) distribuidos homogéneamente en toda la imagen. El error medio cuadrático que se obtuvo durante la rectificación de las imágenes se mantuvo por debajo de 1 pixel, que es aproximadamente 15 metros, muy aceptable.

\section{Procesamiento de las imágenes}

Primeramente se analizó visualmente con ayuda de las bandas del infrarrojo cercano la imagen, ya estas facilitan la delimitación de la costa y el agua de mar (Ver Figura 3 , izquierda), posteriormente se realizó una clasificación no supervisada para agrupar los pixeles de acuerdo al patrón de reflectancia. Esta clasificación fue realizada en arcgis 10.3 con la herramienta iso cluster, asignando 45 clases, y 20 iteraciones, seguidamente la imagen binaria resultante se recodifico a dos clases, a las cuales se les asigno un valor de "1" para el océano y "2" para tierra firme, esto se hizo a efectos de facilitar los procesos de análisis siguientes donde se requiera cuantificar la perdida de área costera (Ver Figura 3, derecha). 


\section{Figura 3. Imágenes clasificadas}
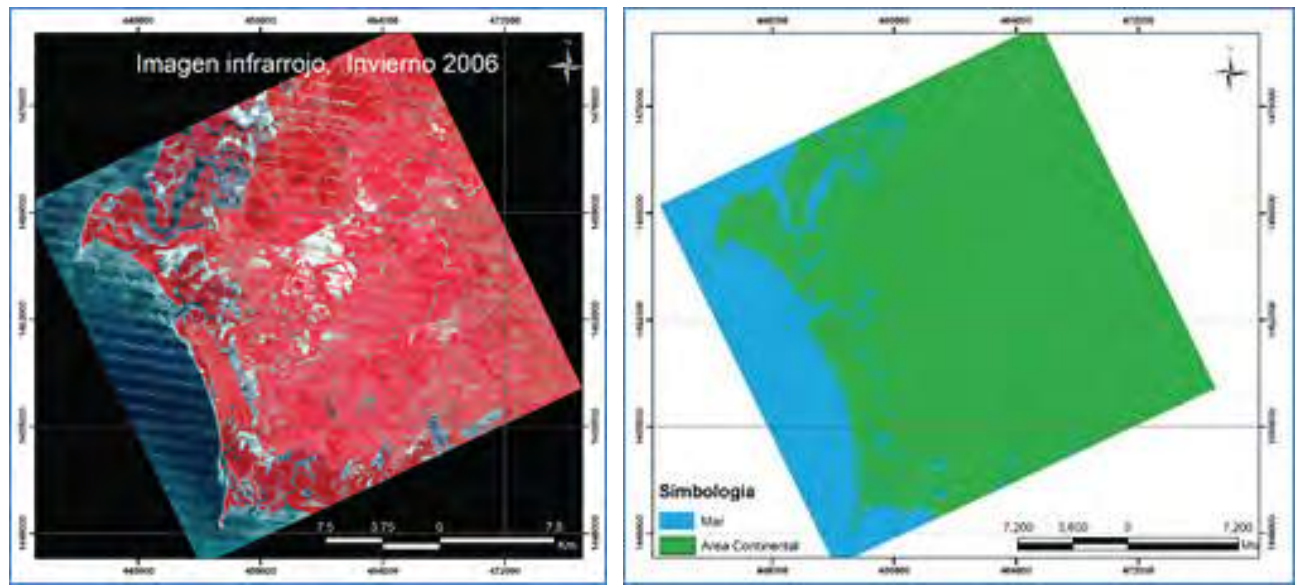

Imágenes correspondientes al infrarrojo cercano (izquierda), Imagen clasificada en 2 clases, área continental y océano (derecha)

(Fuente; Elaboración propia)

La extracción de la línea de costa se realizó vectorizando directamente sobre los pixeles que se encuentra entre el limite húmedo y seco de la playa (imagen recodificada a dos clases), ya que es la zona de la costa que tiene mayor susceptibilidad a sufrir cambios por fenómenos de erosión o acreción, siendo fácilmente identificable por su cambio de reflectividad de arena húmeda a arena seca, lo cual también ayuda a minimizar el efecto de los cambios de mareas que se dan constantemente (ver Figura 3 derecha).

\section{Tasas de cambio}

La tasa de erosión/acreción se analizó apoyándonos en la extensión DSAS versión 4,3 desarrollada por el USGS. Una vez digitalizadas las líneas de costa para cada año, estas se integraron en una geodatabase. Los patrones de movimiento de línea de costa se midieron con respecto a una línea base en alta mar y a lo largo de transectos perpendiculares espaciados a cada 100 metros de distancia (Ver Figura 4), 20 transectos para Los Delgaditos, 29 transectos para Cedeño Centro y 12 transectos para El Edén. El método estadístico usado para calcular las tasas de erosión fue el de regresión lineal, ya que este método toma en cuenta las modificaciones que ha sufrido la playa en su perfil horizontal a lo largo de la escala temporal del estudio (Ver Figura 4). A efectos del estudio usamos la tasa promedio de todos los transectos para cada playa, es de hacer notar que el análisis se hizo tomando en cuenta dos periodos del año, un perfil de verano y otro de invierno. 
Figura 4. Técnica para determinar la tasa de cambio en las playas de La Aldea de Cedeño*

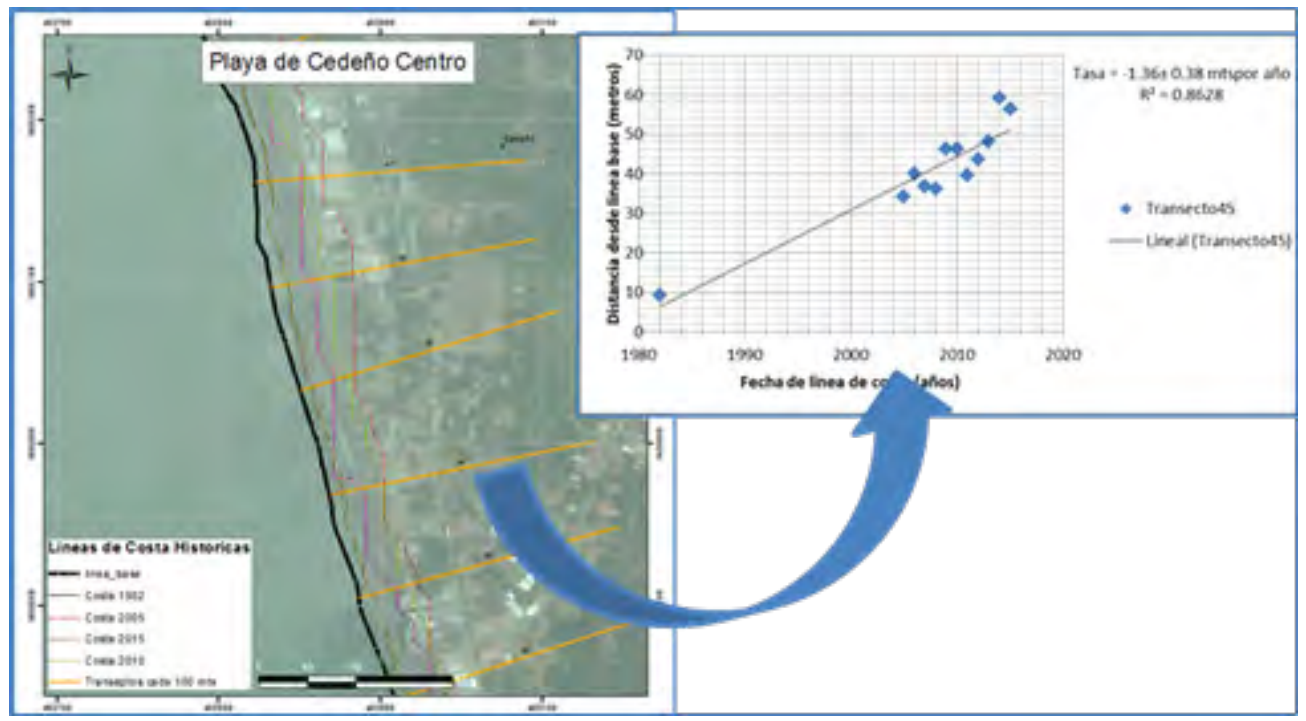

*Líneas de costa históricas y línea base y transectos a cada 100mts. (Izquierda), grafico de regresión lineal (derecha).

(Fuente; Elaboración Propia

\section{RESULTADOS Y DISCUSIÓN}

Se observa que la tendencia general de las 3 playas analizadas, durante el periodo 1982-2015 es erosiva, representando una pérdida del recurso costero (playa). En los gráficos 1, y 2 se muestra el resultado de la tasa de erosión para cada playa, en los dos periodos estacionales del año. Se observa que estadísticamente los valores de la tasa de erosión tienen cierta aleatoriedad, donde los coeficientes de correlación son bajos, en tanto que el intervalo de confianza del 95\% representado por 2 grados de libertad, arroja valores de intervalos de confianza similares o mayores a las mismas tasas de erosión encontradas en cada playa analizada.

En las tablas 2, 3 y 4, se presentan los resultados de las tasas de erosión/acreción conseguidos en el estudio, obteniendo los siguientes resultados: Valores de tasa de erosión muy similares para la playa de Los delgaditos y para Cedeño Centro, esta erosión puede ser originada por las marejadas cíclicas que ahí ocurren, y en menor medida producto del ascenso del nivel del mar y mareas meteorológicas, mientras que en El Edén, la tasa de erosión es baja en comparación con las otras playas, sin 
embargo allí también se da el fenómeno de acreción, pudiendo ser producto de la deriva litoral que transporta sedimentos y los deposita en sus playas.

\section{Gráfico 1. Tasa promedio de erosión, perfil de Verano*}

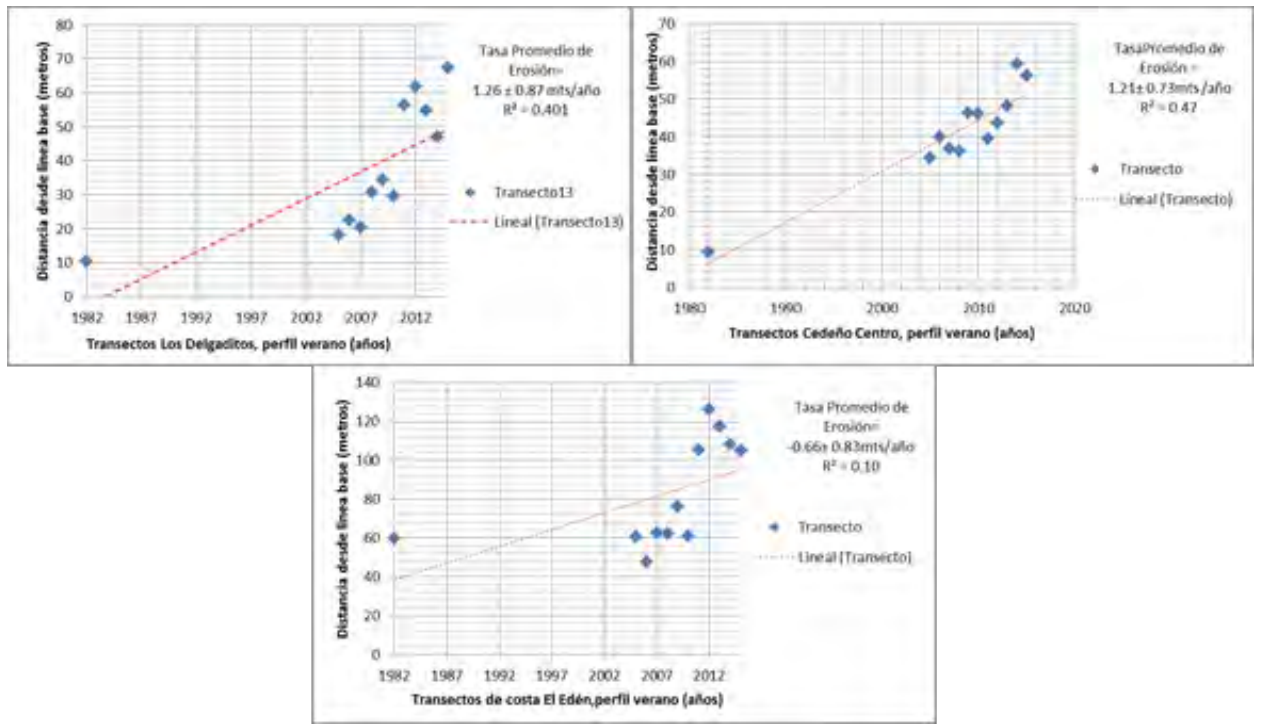

*Playa Los Delgaditos. (Gráfico izquierda), Playa, Cedeño Centro (Gráfico derecha), Playa, El Edén (Gráfico centro).

(Fuente; Elaboración Propia)

\section{Gráfico 2. Tasa promedio de erosión y acreción, perfil de invierno *}

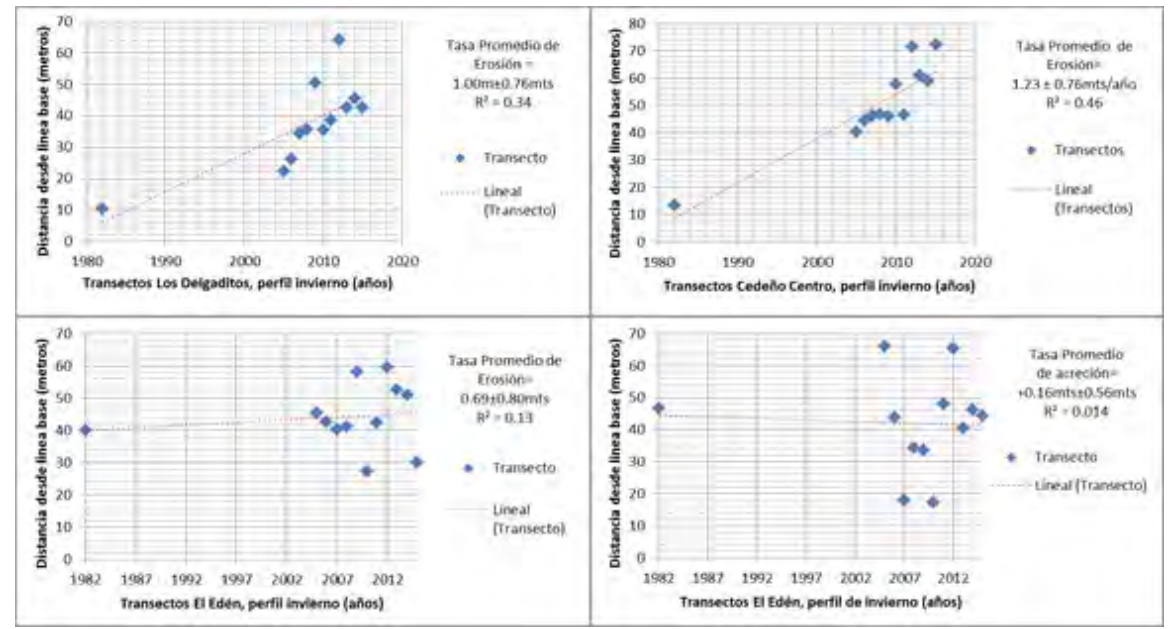

*Playa Los Delgaditos. (Gráfico, izquierda arriba), Playa Cedeño Centro (Gráfico, derecha arriba), Playa El Edén verano (Gráfico, abajo izquierda), Playa El Edén invierno (Gráfico, abajo derecha).

(Fuente; Elaboración Propia) 
Tabla 2. Indicadores de erosión en las playas de la Aldea de Cedeño

\begin{tabular}{|c|c|c|c|c|c|c|c|}
\hline Playa & $\begin{array}{c}\text { Longitud de } \\
\text { playa } \\
\text { analizada(km) }\end{array}$ & $\begin{array}{c}\text { \# de } \\
\text { Transectos } \\
\text { por playa }\end{array}$ & $\begin{array}{c}\text { Tasa } \\
\text { promedio } \\
\text { de erosión } \\
\text { (mts/año) }\end{array}$ & $\begin{array}{c}\text { Valor del intervalo } \\
\text { de confianza (mts) }\end{array}$ & $\begin{array}{c}\text { Retroceso de } \\
\text { linea de costa } \\
\text { entre 1982- } \\
2015(\mathrm{mts})\end{array}$ & $\begin{array}{c}\text { Promedio de } \\
\text { retroceso de } \\
\text { linea de costa } \\
1982-2015 \\
\text { (mts) }\end{array}$ & $\begin{array}{c}\text { Perdida de } \\
\text { playa (Ha) }\end{array}$ \\
\hline Los Delgaditos & 2.35 & 20 & -1.13 & \pm 0.82 & -42.55 & -38.03 & -9.36 \\
\hline Cedeño Centro & 2.91 & 29 & -1.22 & \pm 0.74 & -40.62 & -39.97 & -11.78 \\
\hline ElEdén & 1.95 & $\begin{array}{c}12(7 \\
\text { transectos } \\
\text { en erosión) }\end{array}$ & -0.67 & \pm 0.81 & -27.55 & -44.67 & -1.93 \\
\hline
\end{tabular}

Nota; El valor de retroceso de la línea de costa, corresponde al análisis entre la posición del año más antiguo y el año más reciente. Y el promedio de retroceso de la línea de costa, es la media de todos los valores calculados para el periodo estudiado.

(Fuente; Elaboración Propia)

Tabla 3. Indicadores de acreción en Playa El Edén

\begin{tabular}{|c|c|c|c|c|c|c|c|}
\hline Playa & $\begin{array}{c}\text { Longitud de } \\
\text { playa } \\
\text { analizada(km) }\end{array}$ & $\begin{array}{c}\text { \# de } \\
\text { Transeptos }\end{array}$ & $\begin{array}{c}\text { Tasa } \\
\text { promedio } \\
\text { de acreción } \\
\text { (mts/año) }\end{array}$ & $\begin{array}{c}\text { Intervalo de } \\
\text { confianza (mts) }\end{array}$ & $\begin{array}{c}\text { Progradación } \\
\text { de líneade } \\
\text { costa 1982- } \\
2015(\mathrm{mts})\end{array}$ & $\begin{array}{c}\text { Promedio de } \\
\text { progradación } \\
\text { de línea de } \\
\text { costa 1982- } \\
2015(\mathrm{mts})\end{array}$ & $\begin{array}{c}\text { Ganancia de } \\
\text { playa (Ha) }\end{array}$ \\
\hline El Edén & 1.95 & $\begin{array}{c}12(5 \\
\text { transectos } \\
\text { en acreción) }\end{array}$ & 0.16 & \pm 0.56 & 7.03 & 39.00 & 0.35 \\
\hline
\end{tabular}

Fuente; Elaboración Propia

Tabla 4. Valores promedio de acreción/erosión en las Playas de la Aldea de Cedeño

\begin{tabular}{|c|c|c|c|c|}
\hline \multirow{2}{*}{ Playa } & $\begin{array}{c}\text { Periodo } \\
\text { estacional }\end{array}$ & $\begin{array}{c}\text { Tasa Promedio } \\
\text { de } \\
\text { erosión/acreció } \\
\mathrm{n}(\mathrm{mts})\end{array}$ & $\begin{array}{c}\text { Valor del intervalo } \\
\text { de confianza (mts) }\end{array}$ & $\begin{array}{c}\text { Promedio } \\
\text { retroceso/avan } \\
\text { ce de costa } \\
1982-2015 \\
\text { (mts) }\end{array}$ \\
\hline \multirow{2}{*}{ Los Delgaditos } & Verano & -1.26 & \pm 0.87 & -35.30 \\
\cline { 2 - 5 } & Invierno & -1.00 & \pm 0.76 & -40.76 \\
\hline \multirow{2}{*}{ Cedeño Centro } & Verano & -1.21 & \pm 0.73 & -37.82 \\
\cline { 2 - 5 } & Invierno & -1.23 & \pm 0.76 & -42.12 \\
\hline \multirow{2}{*}{ El Edén } & Verano & -0.66 & \pm 0.83 & -44.94 \\
\cline { 2 - 5 } & Invierno & -0.69 & \pm 0.80 & -44.40 \\
\cline { 2 - 5 } & Invierno & 0.16 & \pm 1.23 & 39.00 \\
\hline
\end{tabular}

Fuente; Elaboración Propia 
En Punta Condega, los resultados se enfocaron a determinar el balance sedimentario (Ver Figura 5), el cual refleja un incremento de la barra litoral próxima al estero de los venados hasta consolidarse con Punta Condega. Tanto en la estación de verano como en la de invierno los resultados son similares, en consecuencia los valores de acreción son mayores que los valores de erosión, expresando un balance sedimentario positivo (Ver Tabla 5), siendo la posible causa de esto, la corriente de deriva litoral en la zona (movimiento de norte a sur), y el aporte de sedimentos del rio Choluteca, el cual desemboca a unos pocos kilómetros al Este de la Aldea de Cedeño.

Figura 5. Consolidación de la barra litoral en Punta Condega* periodo 2005-2015
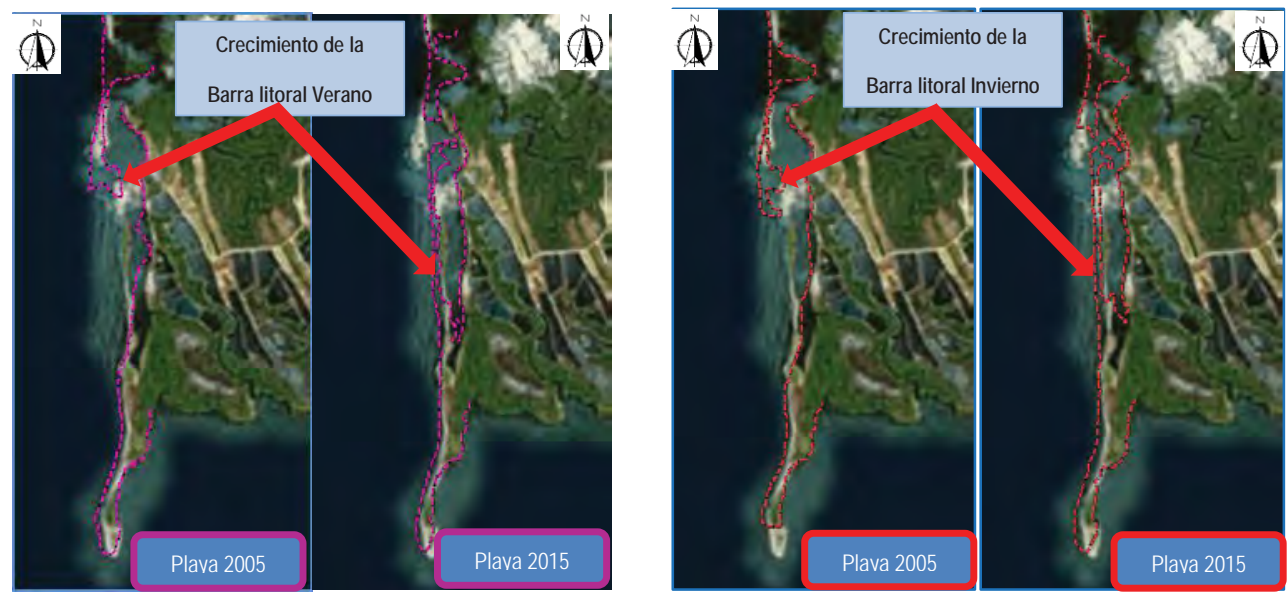

*Líneas de costa en periodo de verano (Izquierda), Líneas de costa en periodo de invierno (derecha). (Fuente; Elaboración Propia)

Tabla 5. Datos de balance sedimentario en Punta Condega

\begin{tabular}{|c|c|c|c|}
\hline $\begin{array}{c}\text { Playa periodo } \\
\text { 2005-2015 }\end{array}$ & Erosión (Ha) & Acreción (Ha) & $\begin{array}{c}\text { Balance } \\
\text { Sedimentario (Ha) }\end{array}$ \\
\hline $\begin{array}{c}\text { Punta condega } \\
\text { Invierno }\end{array}$ & 15.95 & 19.09 & 3.18 \\
\hline $\begin{array}{c}\text { Punta condega } \\
\text { Invierno }\end{array}$ & 6.37 & 19.09 & 12.72 \\
\hline Promedios & $\mathbf{1 1 . 1 6}$ & $\mathbf{1 9 . 0 9}$ & $\mathbf{7 . 9 5}$ \\
\hline
\end{tabular}

Fuente; Elaboración Propia 


\section{CARTOGRAFÍA DE INUNDACIÓN}

\section{Mapa de amenaza de inundación a marejadas}

En la figura 6 se observa el límite actual de la costa para Cedeño Centro, y las zonas con alta susceptibilidad a inundación por marejadas producto del mar de fondo, principal agente modelador en la zona, el área total aproximada de inundación asciende a $17.30 \mathrm{Ha}$, en tanto que el área urbana inundada corresponde a 4 hectáreas. La magnitud de la perdida de playa (Ver Figura 6), es sumamente preocupante, la última Marejada ocurrida en Mayo de 2015, causó una intensa erosión costera, modificando la línea de costa, dañando infraestructuras y ocasionando un desplazamiento de personas hacia sitios más seguros.

Figura 6. Inundación a Marejadas y línea de costa Actual

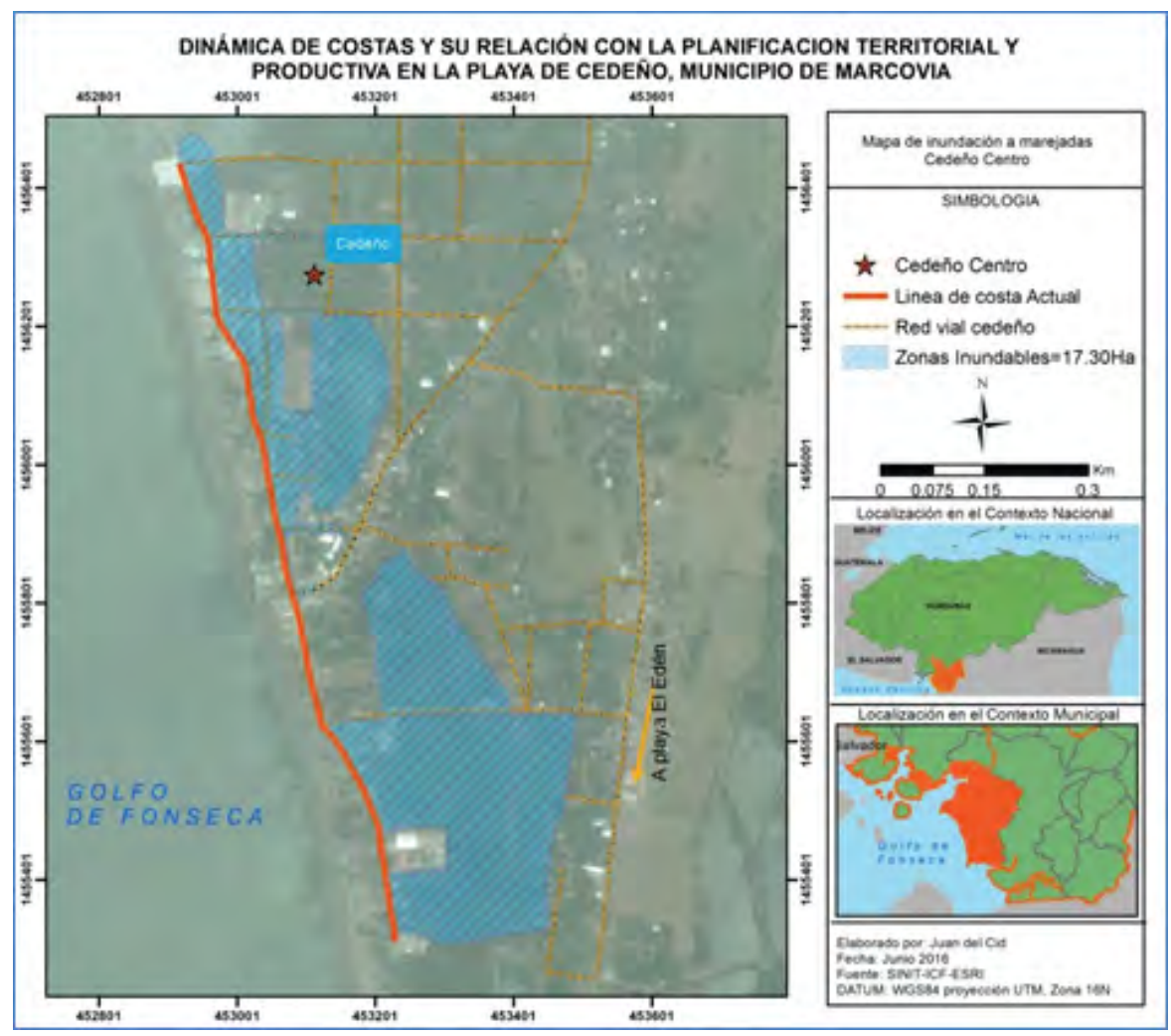

Fuente; Elaboración Propia, ESRI 


\section{Mapa de amenaza ante ascenso del nivel del mar}

La figura 7 muestra la superficie aproximada de inundación por ascenso del nivel del mar, tomando en cuenta el escenario más pesimista de ascenso del mar de $38 \mathrm{~cm}$, proyectado por el IPCC (2013), para el periodo 2046-2065. Estos resultados son aproximados, constituyen apoyo a políticas de ordenamiento, gestión territorial, y gestión de riesgos. El área de inundación proyectada es de $4.28 \mathrm{Ha}$, representando un $8.29 \%$ del territorio urbanizado en la aldea de Cedeño (Ver Figura 7).

\section{Figura 7. Áreas Inundadas por ascenso del nivel del mar escenario 2046-2065}

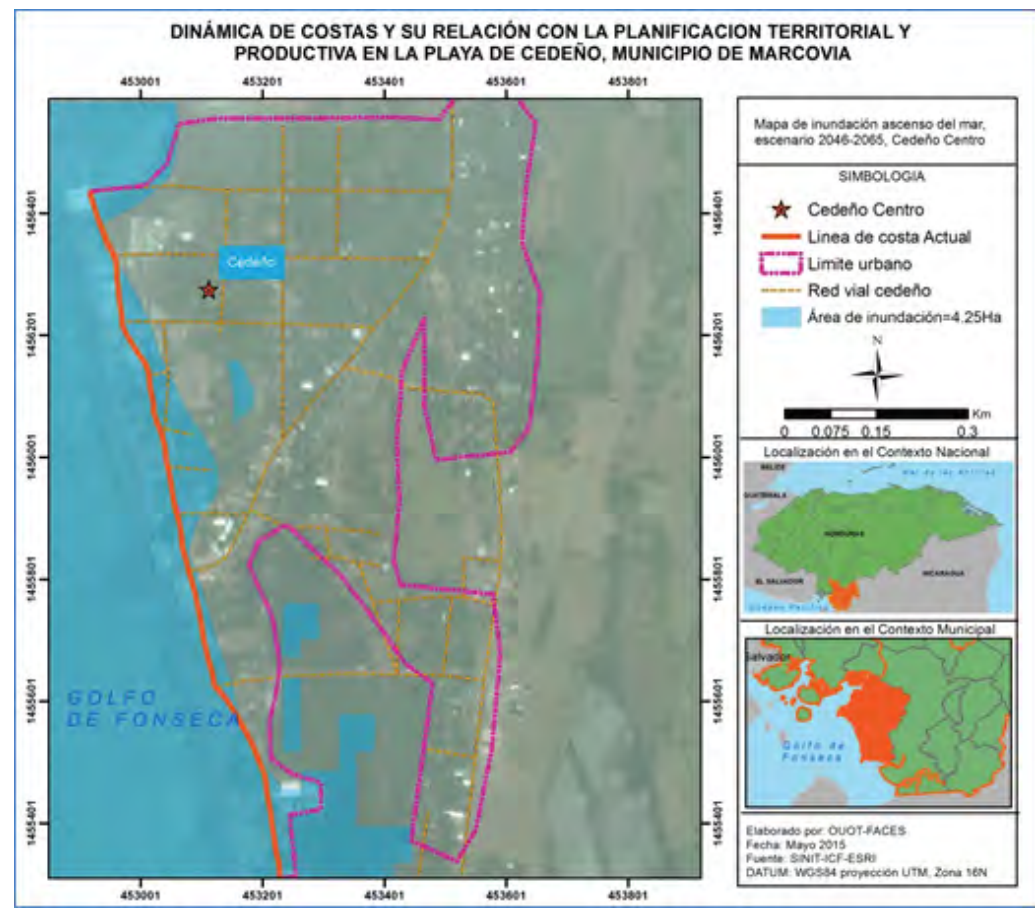

Fuente; Elaboración Propia, ESRI

En tanto que el resultado obtenido para el escenario de inundación por ascenso del nivel del mar al periodo 2081-2100, donde la elevación del mar proyectado es de 82 $\mathrm{cm}$, se muestra en la figura 8. El Área aproximada de inundación por ascenso del nivel del mar en Cedeño Centro, ascenderá a $8.25 \mathrm{Ha}$, representando un 16.18\% del territorio urbanizado de la aldea de Cedeño. Es lógico que el valor se duplique, ya que en este escenario la elevación del mar estimada es casi 2.15 veces mayor a la elevación del mar para el periodo 2046-2065 (Ver Figura 8).). 
Figura 8. Áreas Inundadas por ascenso del nivel del mar escenario 2081-2100



Fuente; Elaboración Propia, ESRI

\section{AGRADECIMIENTOS}

Se agradece a la Universidad Nacional Autónoma de Honduras a través de la Dirección de Investigación Científica y Post Grado (DICyP), por el apoyo brindado a la investigación en concepto de una beca Básica para estudiantes de Post grado, No. 01-2015, adjudicada en la segunda convocatoria del año 2015, también el reconocimiento a las personas del CODEL de Cedeño, y otras personas que proporcionaron asesoría académica y apoyo durante la investigación.

\section{CONCLUSIONES}

1. Las tasas de erosión representan la tendencia que ha tenido la costa en el periodo 1982-2015, sin embargo debido a que los coeficientes de correlación son bajos e en algunos casos los valores del intervalo de confianza son mayores a las propias 
tasas erosión/acreción, no sería adecuado inferir las mismas tasas a un periodo futuro.

2. La playas de la aldea de Cedeño evidencian una tendencia hacia el comportamiento erosivo, en donde Cedeño Centro tiene la tasa de erosión promedio más grande de 1.22 \pm 0.74 metros/año, seguido de Los delgaditos con un tasa de erosión promedio de $1.13 \pm 0.82$ metros, mientras que El Edén tiene un comportamiento atípico en su playa, con una tasa de erosión de $0.67 \pm 1.23$ metros/año en un tramo de su playa (7 de 12 transectos analizados), en tanto que la tasa de acreción en otro tramo de su playa fue de $0.16 \pm 0.56$ metros/año ( 5 de 12 transectos analizados), en cambio Punta Condega tienen un balance sedimentario positivo de $7.95 \mathrm{Ha}$.

3. El comportamiento de retroceso 0 avance en la costa ha sido influenciado principalmente por las marejadas o mar de fondo, que cíclicamente se dan en la zona y que en el año 2015 ha tenido su mayor influencia.

4. El retroceso de costa para Los delgaditos y Cedeño Centro, entre el primero y el último analizado, refleja un movimiento de 42.55 metros y 40.62 metros respectivamente, por otro lado en Los Delgaditos se generaron tanto fenómenos de acreción como erosión.

5. En algunos sitios se han formado dunas lo que ha futuro inmediato también podría ocasionar inundaciones en la zona de Cedeño Centro, producto de las intensas lluvias en la zona, además de crear desbalance en la salinidad del agua, ocasionando la perdida de humedales debido a la falta de drenaje de la escorrentías superficiales hacia la costa.

6. El área de inundación producto de las marejadas cíclicas en Cedeño Centro es muy grande aproximadamente de 17.30 hectáreas, afectando en su mayoría áreas de lagunas y esteros, y en donde el área urbanizada corresponde aproximadamente a 4 hectáreas.

7. Los Escenarios de inundación para los periodos 2045-2061, y 2081-2100 no son nada alentadores, ya que en el primer escenario representaría una pérdida de superficie aproximada de $8.29 \%$ del área urbana de Cedeño Centro, sin embargo para el segundo escenario está perdida de superficie seria 2.15 veces mayor que escenario anterior, siendo esta de $16.18 \%$ del territorio urbano actual.

8. Es de vital importancia dar seguimiento al monitoreo de la costa, a fin de crear una base de datos que nos brinden la facilidad de estimar y comparar las modificaciones ocasionadas al sector litoral, asimismo que sirvan como insumos de apoyo a la toma de decisiones en políticas de ordenamiento, gestión de los territorios y gestión de riesgos, entre otras. 


\section{REFERENCIAS BIBLIOGRÁFICAS}

Castillo Charris, M. A., \& Gamarra Mendoza, E. A. (2014). Análisis multitemporal de la línea de costa en la isla de Tierrabomba y proyección del mapa de inundación por aumento del nivel medio del mar. Bol. Cient. $\mathrm{ClOH}(32), 163-177$.

Fletcher, C. H., Romine, B. M., Genz, A. S., Barbee, M. M., Dyer, M., Anderson, T. R., . . . Richmond, B. M. (2012). National Assessment of Shoreline Change: Historical Shoreline Change in the Hawaiian Islands: U.S. Geological Survey Open-File Report 2011-1051, 55 p. Obtenido de USGS: http://pubs.usgs.gov/of/2011/1051.)

Hantson, S., Chuvieco, E., Pons, X., Domingo, C., Cea, C., Moré, G., . . . Tejeiro, J. A. (Diciembre de 2011). Cadena de pre-procesamiento estándar para las imágenes Landsat del Plan Nacional de Teledetección. Revista de Teledetección, Asociación Española de Teledetección(36), 51-61.

IPCC. (2013). Resumen para responsables de políticas. En: Cambio Climático 2013: Bases físicas. Contribución del Grupo de trabajo I al Quinto Informe de Evaluación del Grupo Intergubernamental de Expertos sobre el Cambio Climatico. Cambridge University Press, Cambridge, Reino Unido y Nueva York, NY, Estados Unidos de América: Stocker, T. F., D. Qin, G.-K. Plattner, M. Tignor, S. K. Allen, J. Boschung, A. Nauels, Y. Xia, V. Bex y P.M.

Ministerio de Medio Mabiente y Recursos Naturales. (2012). Estudio de los Procesos de Erosión Sedimentación Playa El Espino. San Salvador.

Ojeda Zújar, J., Díaz Cuevas, M., Prieto Campos , A., \& Álvarez Francoso , J. (20 de Septiembre de 2013). Línea de Costa y Sistemas de Información Geográfica: Modelo de Datos para la Caracterización y Calculo de Indicadores en la Costa Andaluza. Investigaciones Geográficas Instituto Interuniversitario de Geografía Universidad de Alicante, 60, 37-52. 